\title{
A Community-Based Intervention for Improving Medication Adherence for Elderly Patients with Hypertension in Korea
}

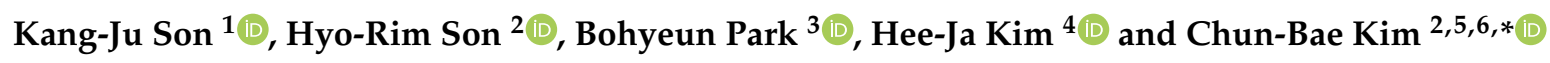 \\ 1 Research Institute for Healthcare Policy, Korean Medical Association, Seoul 04373, Korea; \\ sonkangju@hanmail.net \\ 2 Hongcheon County Hypertension and Diabetes Registration and Education Center, Kangwon Province, \\ Hongcheon 25135, Korea; hc_health@naver.com \\ 3 Hongcheon County Health Center, Kangwon Province, Hongcheon 25135, Korea; pbh0118@korea.kr \\ 4 Hoengseong County Health Center, Kangwon Province, Hoengseong 25220, Korea; Khja1231@korea.kr \\ 5 Department of Preventive Medicine, Yonsei University Wonju College of Medicine, Wonju 26426, Korea \\ 6 Institute for Poverty Alleviation and International Development, Yonsei University, Wonju 26493, Korea \\ * Correspondence: kimcb@yonsei.ac.kr; Tel.: +82-(0)33-741-0344; Fax: +82-(0)33-747-0409
}

Received: 16 December 2018; Accepted: 21 February 2019; Published: 28 February 2019

\begin{abstract}
The chronic disease management program, a community-based intervention including patient education, recall and remind service, and reduction of out-of-pocket payment, was implemented in 2005 in Korea to improve patients' adherence for antihypertensive medications. This study aimed to assess the effect of a community-based hypertension intervention intended to enhance patient adherence to prescribed medications. This study applied a non-equivalent control group design using the Korean National Health Insurance Big Data. Hongcheon County has been continuously implementing the intervention program since 2012. This study involved a cohort of patients with hypertension aged $>65$ and $<85$ years, among residents who lived in the study area for five years (between 2010 and 2014). The final number of subjects was 2685 in both the intervention and control region. The indirect indicators were analyzed as patients' adherence and level of continuous treatment using the difference-in-difference regression. The proportion of hypertensive patients who continuously received insurance benefits for $>240$ days in 2014 was $81.0 \%$ in the intervention region and $79.7 \%$ in the control region. The number of dispensations per prescription and the dispensation days per hypertensive patient in the intervention region increased by approximately $10.88 \%$ and 2.2 days on average by month, respectively, compared to those in the control region. The intervention program encouraged elderly patients with hypertension to receive continuous care. Another research is needed to determine whether further improvement in the continuity of comprehensive care will prevent the progression of cardiovascular diseases.
\end{abstract}

Keywords: hypertension; medication adherence; community-based intervention; difference-indifference regression

\section{Introduction}

The United Nations (UN) reached an agreement titled "Political Declaration of the High-Level Meeting of the General Assembly on the Prevention and Control of Non-Communicable Diseases (NCDs)" in 2011 to respond to the crisis of double burden of NCDs [1]. According to various studies such as the Global Burden of Disease (GBD) Study 2010, GBD Study 2013, and GBD Study 2015 [2-5], NCDs now account for more than one-half of the global burden of disease. Cardiovascular diseases (CVD) account for about one-half of NCD deaths. In addition to health-related behaviors like tobacco 
smoking, unhealthy diet, and physical inactivity, hypertension and diabetes were also the most common risk factors for CVD [6]. Based on recent mortality data on the cause of death released by the National Statistical Office, not only the mortality rate from cerebrovascular diseases but also the burden of NCD, including CVD, steadily increased in Korea [7,8]. Also, significant health inequalities across NCDs, such as hypertension, diabetes, ischemic heart disease, were observed mainly in Korean women [9].

\subsection{Community-Based Intervention for Chronic Disease Management Program}

Community-based interventions for controlling high blood pressure, such as engaging community health workers in hypertension prevention, team-based care to improve blood pressure control, and screening for hypertension, have played a key role in reducing morbidity and mortality from CVD [10]. Of course, the Korean government targeted hypertension and diabetes, the major risk factors for CVD, through the prevention and control program, too. The following community-based interventions were put in place [11]. First, it was recognized to all residents that the community campaign could manage chronic diseases (including hypertension and diabetes) and encourage active treatment after diagnosis. Second, the registration and education program induced early detection of asymptomatic patients with hypertension, self-awareness, and proper care. Third, to strengthen the healthcare system, the government is applying the registration and management programs for controlling hypertension through the chronic care model at the primary care site [12].

In 2005, the Daegu Metropolitan City conducted the demonstration program on high-risk groups of CVD. On this occasion, as of 2018, 19 regions in Korea were operating the registration and education center for hypertension and diabetes. The target group of this community-based intervention includes patients with hypertension and diabetes aged $>30$ years who lived within the place. Primary healthcare institutions and pharmacies that treat hypertension and diabetes in the community also participate as partners of this center. To keep the intervention running, the center is providing a registration fee (about US\$ 1 for patients aged $\geq 65$ years and US $\$ 4$ for those aged 30 64 years) for each patient per year to the clinic. All patients, regardless of their age, are notified of their regular care schedule through the recall and remind service when they missed medical care. Moreover, the center provides health education and counseling services on diseases, nutrition, and exercise to improve chronic diseases self-management for patients. Finally, this center provides subsidies (about US\$ 3 per month per patient) as out-of-pocket payment only to registered elderly patients aged $\geq 65$ years every time he or she receives medical care utilization after registering to improve medication adherence [13,14].

\subsection{Approaches for Assessing Community-Based Intervention to Improve Medication Adherence}

Although several systematic reviews have shown that some community-based interventions are effective to improve blood pressure control in the community $[15,16]$, few studies have looked at the analysis of interventions to enhance medication adherence and blood pressure control in hypertension. Medication adherence is generally defined as the extent to which patients take drugs or medicine as prescribed by their health care providers [17]. The Korea Centers for Disease Control and Prevention (KCDC) developed indicators of medication adherence for hypertension through the Korean National Health Nutrition Survey (KNHANES) and the Community Health Survey [18]. However, they have the following limitations: (1) These indicators provide only fragmentary information by year; (2) because most indicators are produced by cross-sectional studies, individual trends of medication adherence cannot be identified; (3) memory bias may exist due to a survey; and (4) securing representation in a sample survey may be difficult. Consequently, studies involving longitudinal and time-series data are needed for evaluating a community-based hypertension intervention with patients' adherence. 
Korea has already achieved mandatory universal health coverage since 1989 with the national health insurance system. The National Health Insurance Service (NHIS) developed the Korean National Health Insurance (KNHI) Big Data platform in 2016 [19]. Thus, this KNHI Big Data can identify the actual medical use, which cannot be identified in the survey. In particular, individual and collective medical care utilization can be tracked by establishing an entire population cohort [18]. A study using the KNHI Big Data should be conducted to understand how patients with hypertension change not only their medical care utilization but also medication adherence over time [20-23].

Therefore, this study aimed to determine whether there was a difference in the medication adherence among elderly patients with hypertension using personalized health information data of the KNHI before and after the community-based intervention in Korea.

\section{Materials and Methods}

\subsection{Research Design and Study Region}

This study used a non-equivalent control group design that assessed patients with hypertension in the regions regarding whether the community-based intervention was implemented or not. In addition, at the beginning of the study period, a cohort design that could set up and track the study population was selected.

The community-based intervention for managing hypertension had been implemented for 6 years is Hongcheon County. This program was launched in July 2012 and is still ongoing. During the early stage, 7 sub-health centers and 2 clinics were only starting. Currently, 7 sub-health centers, 22 clinics, and 17 pharmacies have participated all together as partners. In particular, the registration rate was $100 \%$ for elderly hypertensive patients over 65 years old as of 2018. Thus, Hongcheon County was selected as an intervention region [13]. Hoengseong County is geographically close to Hongcheon County and has a very similar population structure as Kangwon Province. Hoengseong County is carrying out the prevention program for CVD to promote the health statuses of residents; however, the community-based intervention was not yet implemented. Thus, Hoengseong County was selected as the control region.

\subsection{Data and Study Subjects}

Figure 1 shows the process of extracting customized data requested from the NHIS (approval no. NHIS-2018-1-110) for this study. Considering the case of Hongcheon County, it was designated as a research period for every two years, 2010-2014, before and after implementing the program. Study subjects in the intervention and control regions were operationally defined as patients who were prescribed anti-hypertensive drugs after being diagnosed with hypertension. Hypertensive patients were identified according to the ICD-10 codes I10-I15 in the database. Moreover, the anti-hypertensive drug used was classified as 214 (blood pressure reduction drug) based on the No. 196 Operating Procedure (legislation on 2009.8.24) "Regulations on Drugs and Other Classification Numbers" of the Food and Drug Safety Administration [19].

In order to assess the effectiveness of this intervention program, patients with similar characteristics in both the intervention and control regions should be selected in order to track and observe them for the same study period. Therefore, this study was limited to elderly patients with hypertension aged over 65 and under 85 years old, among residents who lived in each district for 5 years between 2010 and 2014. Patients aged $<85$ years were selected in 2010 because the assessment of program effectiveness was considered meaningless as the participation of the super-aging population (aged $\geq 85$ years) was expected to be difficult [24].

As of 2010, the population in the intervention region was 21,783 people aged $\leq 29$ years, 34,718 aged $30 \sim 64$ years, 11,950 aged $64 \sim 84$ years, and 1002 aged $\geq 85$ years. The total population was 69,453 . As of the same year, the population in the control region was 12,919 people aged $\leq 29$ years, 21,686 aged $30 \sim 64$ years, 8671 aged $64 \sim 84$ years, and 757 aged $\geq 85$ years. Overall, the total population 
was 44,033 . Regarding the overall population, the intervention region had an approximately 1.58 times higher population size than the control region. According to the current status of the population living continuously for 5 years between 2010 and 2014, based on the eligibility database of the KNHI Big Data, the number of people over 65 years old who were essential for participating in the program was 10,573 in the intervention region and 7648 in the control region. The study subjects comprised 4950 patients aged 65 84 years with hypertension in the intervention region and 3664 in the control region (Figure 1).

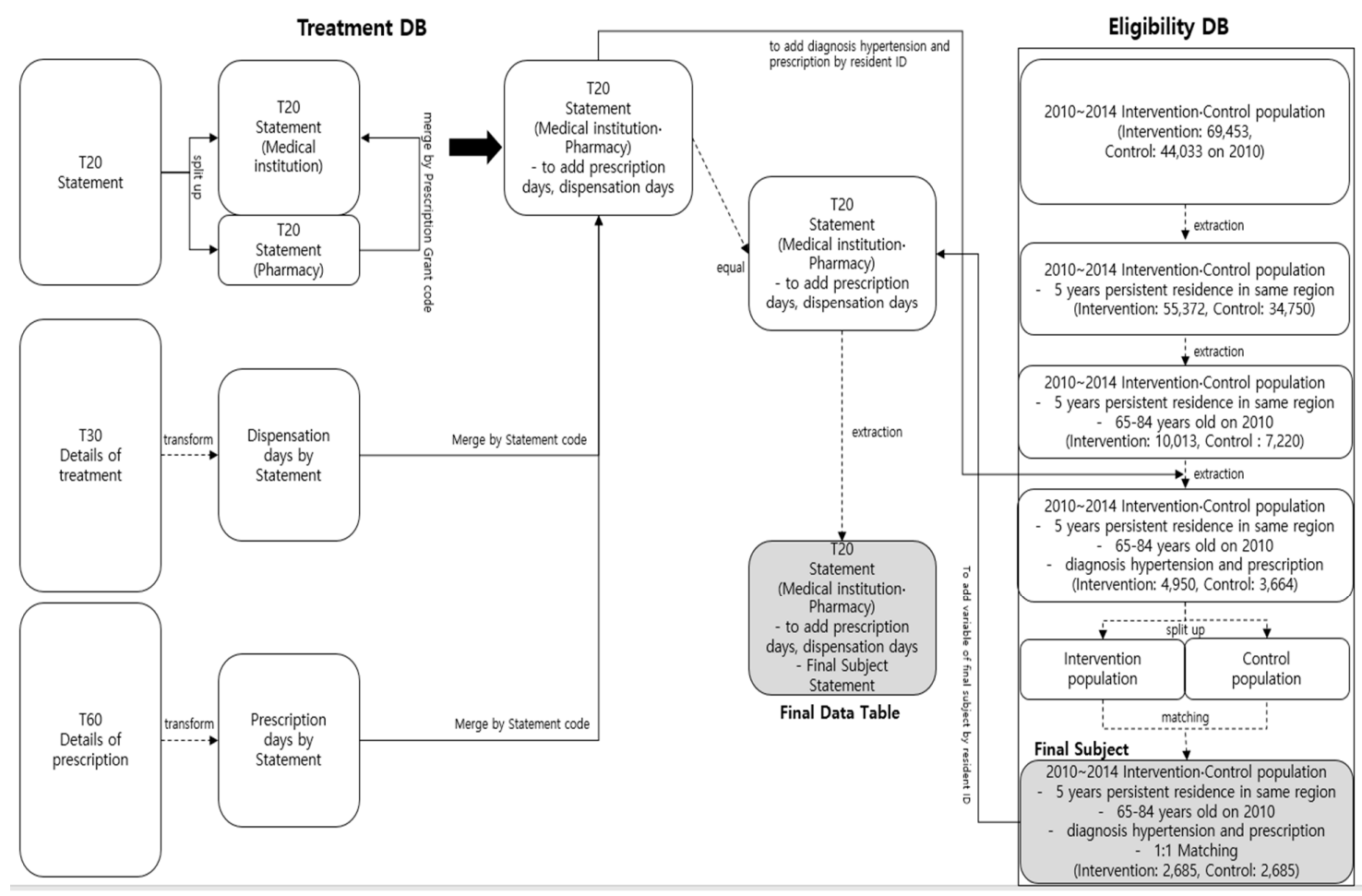

Figure 1. Flowchart for selecting study subjects using the Korean National Health Insurance (KNHI) Big Data on the community-based intervention program.

\subsection{1:1 Matching for Coping with Confounders}

To eliminate the influence of strong constitutional confounders like age and sex of study subjects [25], individual matching methods were used in this study. The variables used for individual matching were age, gender, type of subscription, and income rank as insurance premium level in patients with hypertension, as typical demographic variables, which are the eligibility criteria in the KNHI Big Data.

The subscriber classification is divided into three types: self-employed, employee, and medical aid. It is further classified into two categories: household and household members (or dependent). Workers and employers, public officials, and faculty at all sites are registered employees. The self-employed refer to members other than insured employees and their dependents. The medical aid group refers to individuals with a difficult life according to the National Basic Living Security Act, Disaster Relief Act, and Act on Honorable Treatment of and Support for Persons who Died or were Injured for the Public Good. Household members (or dependents) are persons who primarily depend on the self-employed, employee, and medical aid [26]. Through 6 types of subscription, one can determine the income and lifestyle of the subjects.

The premium category is a variable that divides the premium paid by the subscriber into 20 sub-categories. Generally, these are allocated between 1 and 20 sub-categories depending on their income. The higher the income, the higher the sub-category. However, if for the beneficiary of medical aid, the premium is not charged or charged after the event, they are entered as missing [19]. 
In this study, the beneficiary of medical aid had the premium sub-category as zero (0), and others were considered "missing." The level of income can be indirectly determined through the sub-category of premiums. Therefore, we divided the five sub-groups for income rank. The I group of income rank is included in the 0th to 4th sub-categories; the II group, 5th 8th; the III group, 9th 12th; the IV group, 13th 16th; and the V group, 17th 20th. Each of the missing values and the 0 20th sub-categories were used for matching.

Based on these variables, the same patients were exactly matched in a 1:1 ratio. If two patients with the same variables were found in the intervention and control groups, they were matched. Moreover, if more than one case had the same variables, a random number of individuals within the group was given and matched.

\subsection{Investigating Indicators for Medication Adherence}

Based on the Andersen model [27], the community-based intervention is a chronic disease management program for addressing the enabling and need factors. It directly supports medical care and pharmaceutical costs, thereby increasing the possibility of medical service use for improving medication adherence. Moreover, health education and counseling services are increasing the awareness regarding medication adherence in a small way. Medication adherence may be measured indirectly or directly. Two indirect adherence metrics used in research and administrative settings are the medication possession ratio (MPR) and the proportion of days covered (PDC). These measures rely on pharmacy on insurance claims data. In clinical settings, adherence may be indirectly assessed using not only patient recall (self-report, questionnaire) but also other methods such as pill counting, dose counting device, and electronic prescribing, Direct methods, including observed therapy, and blood or urine drug and metabolite concentrations are most commonly used in research [28-30]. In this study, we modified the data used in the NHIS to suit the measurement used in research and administrative settings. Therefore, this study used the number of patients and proportion using insurance benefit days for the treatment of hypertension based on year and region, dispensation per prescription (DPP), and dispensation days per patient (DDPP) with hypertension as proxy indicators [31].

The number of patients and proportion by insurance benefit days for the treatment of hypertension by year indicates how many patients with hypertension have been continuously managed within the year. In chronic disease management program, the frequency of visits greatly varies depending on the patient's long-term conditions and the nature of medical institutions. In order to determine whether a patient is continuously visiting for hypertension treatment, the total number of insurance benefit days per year was assessed. The insurance benefit days refers to the number of days on which the medication was prescribed to the patient on the date the patient visited the medical institution. Therefore, beneficiaries with $\geq 240$ days were defined as patients with continuous treatment in this study, which is about two-thirds of the number of days covered by the NHIS within the year (i.e., 365 days.) The DPP indicator provides an indication of the patients' adherence with the treatment in a medical institution. Moreover, the "DDPP with hypertension" indicator shows the average dispensation days per month for a number of patients with hypertension within a community, and the size of medical care was evaluated as an individual unit.

\subsection{Statistical Analysis}

Firstly, in order to determine the homogeneity of study subjects between the intervention and control regions, the descriptive analysis including the t-test and chi-square test were used.

Secondly, we established the dummy variable (time) before and after introducing the program and the dummy variable (region) that distinguish the districts regarding whether the program was introduced or not to apply the difference-in-difference (DID) regression methodology. In this study, if the district was an intervention group, region was considered 1 , and if the district was a control group, region was taken to be 0 (zero). Moreover, if the study period was from January 2010 to 
December 2011, time was 0 (zero), and if the study period was from January 2013 to December 2014, time was 1 . The DID regression analysis excluded the one-year period in 2012. This is because the period for normalization after implementing the program was considered 6 months. As it excluded 6 months after the program, it also excluded 6 months before the program in order to match the preand post-intervention periods. After creating the "DID" variable by multiplying region and time, a regression analysis was performed [32].

$$
\begin{aligned}
& y=\text { intercept }+\beta_{1} \text { region }+\beta_{2} \text { time }+\beta_{3} D I D \\
& \text { region }\left\{\begin{array} { c } 
{ 1 = \text { Hongcheon } } \\
{ 0 = \text { Hoengseong } }
\end{array} , \text { time } \left\{\begin{array}{l}
1=201301 \sim 201412 \\
0=201001 \sim 201112
\end{array},\right.\right. \\
& D I D=\text { region } \times \text { time }
\end{aligned}
$$

We set the indicator that can represent the effects as a dependent variable $(y)$. Using these, we performed a regression analysis to estimate the intercept and coefficients $\left(\beta_{1}, \beta_{2}, \beta_{3}\right)$. The intercept is the average value $(y)$ of a region that did not implement the program before it was introduced. $\beta_{1}$ is the difference of the average value $(y)$ between the region that either implemented or did not implement the community-based intervention before it was introduced. Therefore, the difference between regions may be determined before the introduction of the program. $\beta_{2}$ is the difference of the average values $(y)$ between pre-intervention and post-intervention periods in a region where the community-based intervention is not implemented. Therefore, it corresponds to the natural increase in $y . \beta_{3}$ is the difference in the average value $(y)$ before and after implementing the intervention in the region where the program was introduced, minus the difference in the average value $(y)$ before and after implementing the intervention in the region where the program was not introduced.

The data of this study was extracted and provided by the KNHI Big Data in accordance with the study purpose and did not include the identification of patients' personal unique information. For the ethical consideration of this study, the review exemption was also approved by the Institutional Review Board of Yonsei University Wonju Severance Christian Hospital (approval no. CR317342).

\section{Results}

\subsection{Comparison of Demographic Characteristics for Final Study Subjects Pre-Matching and Post-Matching between Study Regions}

Table 1 shows the result of the homogeneity test for the final study subjects pre-matching and post-matching between the intervention and control regions. According to the basic eligibility information before matching, the 1:1 match was done so that the final study subjects for the intervention and control region were similar, from the gender-to-age ratio to the level of income. The final number of subjects for the 1:1 match was 2685 in the intervention region and 2685 in the control region.

For homogeneity tests, age, which is a continuous variable, was tested using the t-test, whereas the categorical variables, gender, type of subscription, and income rank, were evaluated using the chi-square test. Prior to matching, the study subjects between the intervention and control regions had almost similar distributions of gender ratio and income ranks; however, the distributions for age and type of subscription yielded statistically significant differences between the two regions. After matching, the final study subjects between the intervention and control regions could be observed to have the same demographic characteristics, from the perspectives of predisposing factors on the Andersen model.

Of course, since they were hypertensive patients, they all need chronic disease management services to prevent complications of severe CVD. 
Table 1. Results of homogeneity test on final study subjects according to matching between study regions: Predisposing and need factors on the Andersen model.

\begin{tabular}{|c|c|c|c|c|c|c|c|c|c|c|}
\hline \multicolumn{6}{|c|}{ Pre-Matching } & \multicolumn{5}{|c|}{ Post-Matching } \\
\hline \multicolumn{11}{|c|}{ Continuous Variable } \\
\hline & \multicolumn{2}{|c|}{ Intervention Region } & \multicolumn{2}{|c|}{ Control Region } & \multirow[t]{2}{*}{$p$} & \multicolumn{2}{|c|}{ Intervention Region } & \multicolumn{2}{|c|}{ Control Region } & \multirow[t]{2}{*}{$p$} \\
\hline & $\mathrm{n}_{1}$ & Mean (SD) & $\mathbf{n}_{2}$ & Mean (SD) & & $\mathrm{n}_{3}$ & Mean (SD) & $\mathrm{n}_{4}$ & Mean (SD) & \\
\hline Age (years) & 4950 & $\begin{array}{l}72.33 \\
(4.91) \\
\end{array}$ & 3664 & $\begin{array}{l}72.71 \\
(4.96) \\
\end{array}$ & 0.0120 & 2685 & $\begin{array}{l}72.38 \\
(4.74) \\
\end{array}$ & 2685 & $\begin{array}{l}72.38 \\
(4.74) \\
\end{array}$ & 1 \\
\hline \multicolumn{11}{|c|}{ Categorical variables } \\
\hline & $\mathrm{n}$ & $\%$ & $\mathrm{n}$ & $\%$ & & $\mathrm{n}$ & $\%$ & $\mathrm{n}$ & $\%$ & \\
\hline \multicolumn{11}{|l|}{ Gender } \\
\hline Male & 1846 & 37.29 & 1385 & 37.80 & \multirow{2}{*}{0.6307} & 934 & 34.79 & 934 & 34.79 & \multirow{2}{*}{1} \\
\hline Female & 3104 & 62.71 & 2279 & 62.20 & & 1751 & 65.21 & 1751 & 65.21 & \\
\hline \multicolumn{11}{|c|}{ Type of subscription } \\
\hline Self-employed & 1156 & 23.35 & 749 & 20.44 & \multirow{6}{*}{0.0015} & 510 & 18.99 & 510 & 18.99 & \multirow{6}{*}{1} \\
\hline $\begin{array}{c}\text { Self-employed } \\
\text { dependents }\end{array}$ & 695 & 14.04 & 457 & 12.47 & & 296 & 11.02 & 296 & 11.02 & \\
\hline Employee & 115 & 2.32 & 99 & 2.70 & & 32 & 1.19 & 32 & 1.19 & \\
\hline $\begin{array}{l}\text { Employee } \\
\text { dependents }\end{array}$ & 2597 & 52.46 & 2034 & 55.51 & & 1585 & 59.03 & 1585 & 59.03 & \\
\hline $\begin{array}{l}\text { Medical aid } \\
\text { households }\end{array}$ & 309 & 6.24 & 258 & 7.04 & & 209 & 7.78 & 209 & 7.78 & \\
\hline $\begin{array}{l}\text { Medical aid } \\
\text { dependents }\end{array}$ & 78 & 1.58 & 67 & 1.83 & & 53 & 1.97 & 53 & 1.97 & \\
\hline \multicolumn{11}{|l|}{ Income rank * } \\
\hline I & 963 & 20.13 & 768 & 21.41 & \multirow{5}{*}{0.3336} & 535 & 20.40 & 535 & 20.40 & \multirow{5}{*}{1} \\
\hline II & 481 & 10.06 & 375 & 10.45 & & 208 & 7.93 & 208 & 7.93 & \\
\hline III & 675 & 14.11 & 511 & 14.25 & & 330 & 12.59 & 330 & 12.59 & \\
\hline IV & 1163 & 24.32 & 810 & 22.58 & & 626 & 23.87 & 626 & 23.87 & \\
\hline $\mathrm{V}$ & 1501 & 31.38 & 1,123 & 31.31 & & 923 & 35.20 & 923 & 35.20 & \\
\hline
\end{tabular}

Figures are frequencies (column percent). N, number. ${ }^{*}$ Total may not match due to missing values

\subsection{Comparison of Healthcare Resources between Study Regions}

Table 2 shows the characteristics of healthcare resource distribution between the intervention and control regions. Across all types, the medical institutions in the intervention region were slightly larger than those in the control region. In both regions, the number of medical institutions was higher in 2014 compared to 2010. The institutions closely related to the community-based intervention are clinics for internal medicine class and pharmacies. Comparing the population-to-healthcare resources, healthcare resource indicators in the intervention region were slightly higher than those in the control region, but with no significant difference. Healthcare resource indicators based on pharmacies were very similar in both regions. From the perspectives of enabling factors in the Andersen model, the distribution of healthcare resources in the intervention and control regions was similar.

Table 2. Comparison of healthcare resources between study regions: Enabling factors on the Andersen model.

\begin{tabular}{|c|c|c|c|c|c|c|c|c|c|c|}
\hline & \multicolumn{5}{|c|}{ Intervention Region } & \multicolumn{5}{|c|}{ Control Region } \\
\hline & 2010 & 2011 & 2012 & 2013 & 2014 & 2010 & 2011 & 2012 & 2013 & 2014 \\
\hline \multicolumn{11}{|l|}{ Healthcare Institutions } \\
\hline Clinic & 29 & 27 & 28 & 28 & 29 & 13 & 13 & 12 & 13 & 12 \\
\hline Health center & 1 & 1 & 1 & 1 & 1 & 1 & 1 & 1 & 1 & 1 \\
\hline Health sub-center & 8 & 8 & 8 & 8 & 8 & 8 & 8 & 8 & 8 & 8 \\
\hline Health post & 18 & 18 & 18 & 18 & 18 & 8 & 8 & 8 & 8 & 8 \\
\hline Pharmacy & 25 & 25 & 24 & 24 & 26 & 15 & 15 & 14 & 15 & 17 \\
\hline Total & 81 & 79 & 79 & 79 & 82 & 45 & 45 & 43 & 45 & 46 \\
\hline \multicolumn{11}{|l|}{ Resource $^{*}$ per 1000 population ${ }^{+}$(on clinic) } \\
\hline No. of clinic per 1000 population & 0.42 & 0.39 & 0.40 & 0.40 & 0.41 & 0.30 & 0.30 & 0.27 & 0.29 & 0.27 \\
\hline No. of bed per 1000 population & 3.15 & 3.12 & 2.95 & 2.94 & 2.89 & 1.09 & 0.68 & 0.68 & 0.67 & 0.67 \\
\hline No. of physician per 1000 population & 0.52 & 0.49 & 0.49 & 0.50 & 0.53 & 0.34 & 0.34 & 0.29 & 0.31 & 0.29 \\
\hline No. of nurse per 1000 population & 0.29 & 0.29 & 0.30 & 0.27 & 0.26 & 0.05 & 0.02 & 0.02 & 0.02 & 0.02 \\
\hline \multicolumn{11}{|l|}{ Resource * per 1000 population (on pharmacy) } \\
\hline No. of pharmacy per 1000 population & 0.36 & 0.36 & 0.35 & 0.34 & 0.37 & 0.34 & 0.34 & 0.32 & 0.34 & 0.38 \\
\hline No. of pharmacist per 1000 population & 0.48 & 0.45 & 0.43 & 0.46 & 0.49 & 0.36 & 0.36 & 0.32 & 0.34 & 0.38 \\
\hline
\end{tabular}

* The Korean National Health Information Database among Korean National Health Insurance (KNHI) Big Data;

+ Resident population by year and region 


\subsection{Comparison of Medication Adherence for Assessing Community-Based Intervention}

Table 3 shows the trends in the number of patients by insurance benefit days for the treatment of hypertension between the intervention and control regions. Finally, 2685 subjects through matching were selected at the baseline. Among them, 2174 patients received continuous insurance benefits for $\geq 240$ days in 2014 in the intervention region. In other words, it was about $81.0 \%$ of the total number of patients. On the other hand, 2138 patients were included in the control region, comprising about $79.7 \%$ of the total number of patients. We could observe that the number of patients with continuous treatment in the intervention region was higher than that in the control region. On the contrary, those with zero insurance benefit days in 2014 were 221 in the intervention region, about $8.2 \%$ of the total number of patients. In addition, in the control region, 229 patients had zero insurance benefit days in 2014, about $8.5 \%$ of the total number of patients. In the control region, the number of patients with zero insurance benefit days was slightly higher than that in the intervention region.

Table 3. Comparison of insurance benefit days * for treating hypertension between study regions.

\begin{tabular}{ccccccccccc}
\hline Region & \multicolumn{9}{c}{ Intervention Region } & \multicolumn{6}{c}{ Control Region } \\
\hline Year & $\mathbf{2 0 1 0}$ & $\mathbf{2 0 1 1}$ & $\mathbf{2 0 1 2}$ & $\mathbf{2 0 1 3}$ & $\mathbf{2 0 1 4}$ & $\mathbf{2 0 1 0}$ & $\mathbf{2 0 1 1}$ & $\mathbf{2 0 1 2}$ & $\mathbf{2 0 1 3}$ & $\mathbf{2 0 1 4}$ \\
\hline Study & 2685 & 2685 & 2685 & 2685 & 2685 & 2685 & 2685 & 2685 & 2685 & 2685 \\
subjects & $(100.0)$ & $(100.0)$ & $(100.0)$ & $(100.0)$ & $(100.0)$ & $(100.0)$ & $(100.0)$ & $(100.0)$ & $(100.0)$ & $(100.0)$ \\
& 0 & 152 & 162 & 194 & 221 & 0 & 134 & 150 & 192 & 229 \\
0 & $(0.0)$ & $(5.7)$ & $(6.0)$ & $(7.2)$ & $(8.2)$ & $(0.0)$ & $(5.0)$ & $(5.6)$ & $(7.2)$ & $(8.5)$ \\
& 311 & 178 & 160 & 150 & 189 & 311 & 175 & 176 & 179 & 224 \\
$1 \sim 179$ & $(11.6)$ & $(6.6)$ & $(6.0)$ & $(5.6)$ & $(7.0)$ & $(11.6)$ & $(6.5)$ & $(6.6)$ & $(6.7)$ & $(8.3)$ \\
& 146 & 112 & 104 & 83 & 101 & 143 & 121 & 122 & 98 & 94 \\
$180 \sim 239$ & $(5.4)$ & $(4.2)$ & $(3.9)$ & $(3.1)$ & $(3.8)$ & $(5.3)$ & $(4.5)$ & $(4.5)$ & $(3.7)$ & $(3.5)$ \\
& 1098 & 1012 & 1056 & 963 & 894 & 1101 & 1127 & 1043 & 1005 & 885 \\
$240 \sim 359$ & $(40.9)$ & $(37.7)$ & $(39.3)$ & $(35.9)$ & $(33.3)$ & $(41.0)$ & $(42.0)$ & $(38.9)$ & $(37.4)$ & $(33.0)$ \\
& 1130 & 1231 & 1203 & 1295 & 1280 & 1130 & 1128 & 1194 & 1211 & 1253 \\
$\geq 360$ & $(42.1)$ & $(45.9)$ & $(44.8)$ & $(48.2)$ & $(47.7)$ & $(42.1)$ & $(42.0)$ & $(44.5)$ & $(45.1)$ & $(46.7)$ \\
\hline
\end{tabular}

Figures are frequencies (column percent). * Total percentage may not match to 100 due to rounding.

Table 4 shows the result of the difference-in-difference regression analysis based on the intervention and control regions, and the pre-intervention and post-intervention periods, using the proxy indicators for medication adherence for treating hypertension. After implementing the community-based intervention for chronic diseases management program, the cases of DPP in the intervention region increased approximately $10.88 \%$ on average per month over the control region (Figure 2). Moreover, the DDPP with hypertension in the intervention region increased by 2.2 days on average per month over the control region (Figure 2). In other words, patients with hypertension in the intervention region had been more on medication for about 26.4 days ( 2.2 days $\times 12$ months) during one year than those in the control region.

Table 4. The result of difference-in-difference regression analysis using the indicators for medication adherence to patients with hypertension.

\begin{tabular}{ccccc}
\hline Indicator & Variable & $\boldsymbol{\beta}$ & $\boldsymbol{t}$ & $\boldsymbol{p}$-Value \\
\hline \multirow{3}{*}{ Dispensation per } & Intercept & 13.36 & 45.68 & $<0.0001$ \\
prescription (DPP) & Region & 10.16 & 24.56 & $<0.0001$ \\
& Time & 4.80 & 11.60 & $<0.0001$ \\
& DID & 10.88 & 18.59 & $<0.0001$ \\
\hline \multirow{2}{*}{ Dispensation days } & Intercept & 3.07 & 31.62 & $<0.0001$ \\
per patient (DDPP) & Region & 2.28 & 16.62 & $<0.0001$ \\
with hypertension & Time & 1.38 & 10.06 & $<0.0001$ \\
& DID & 2.20 & 11.34 & $<0.0001$ \\
\hline
\end{tabular}

DID: 'Difference-in difference' variable by multiplying region and time according to equation. 


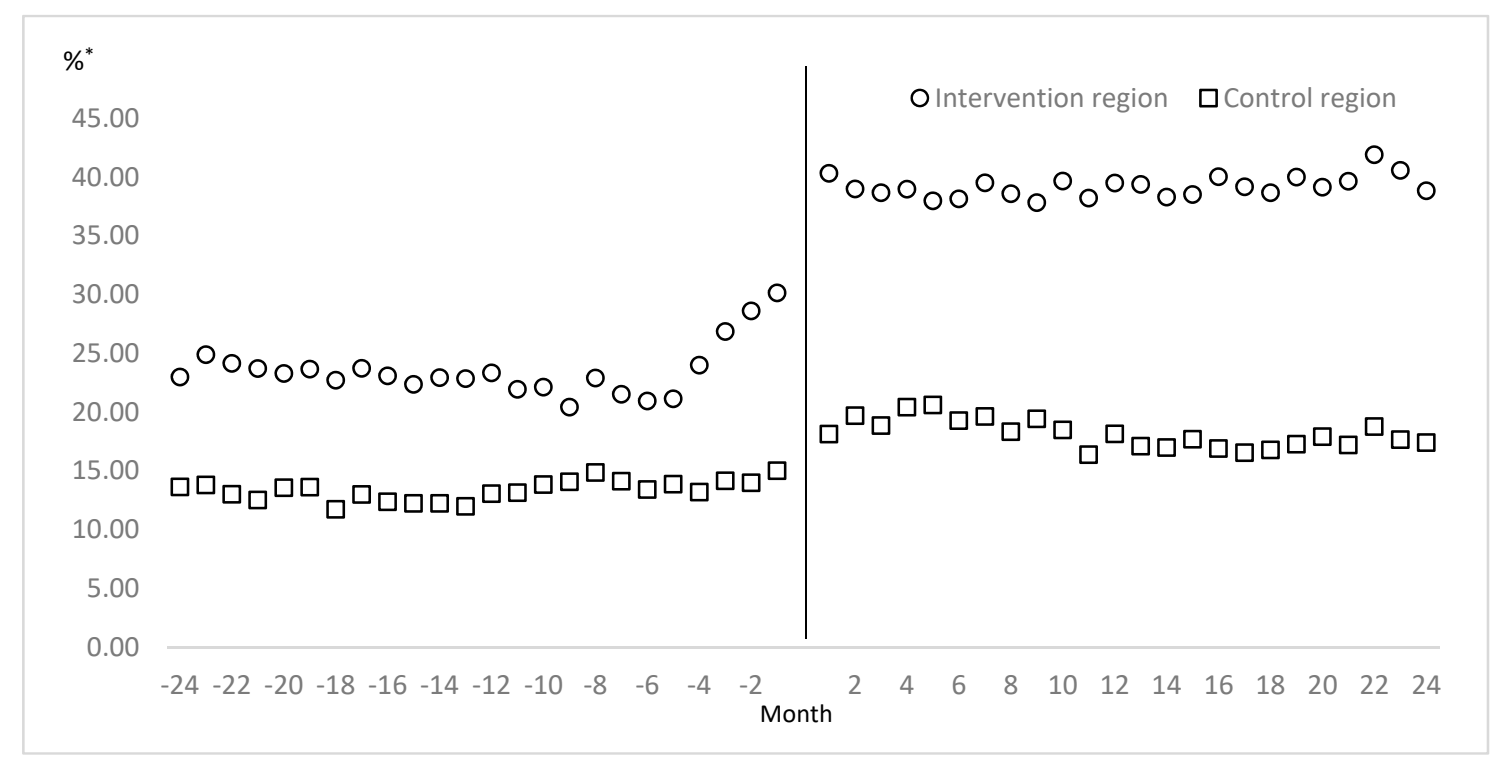

(a)

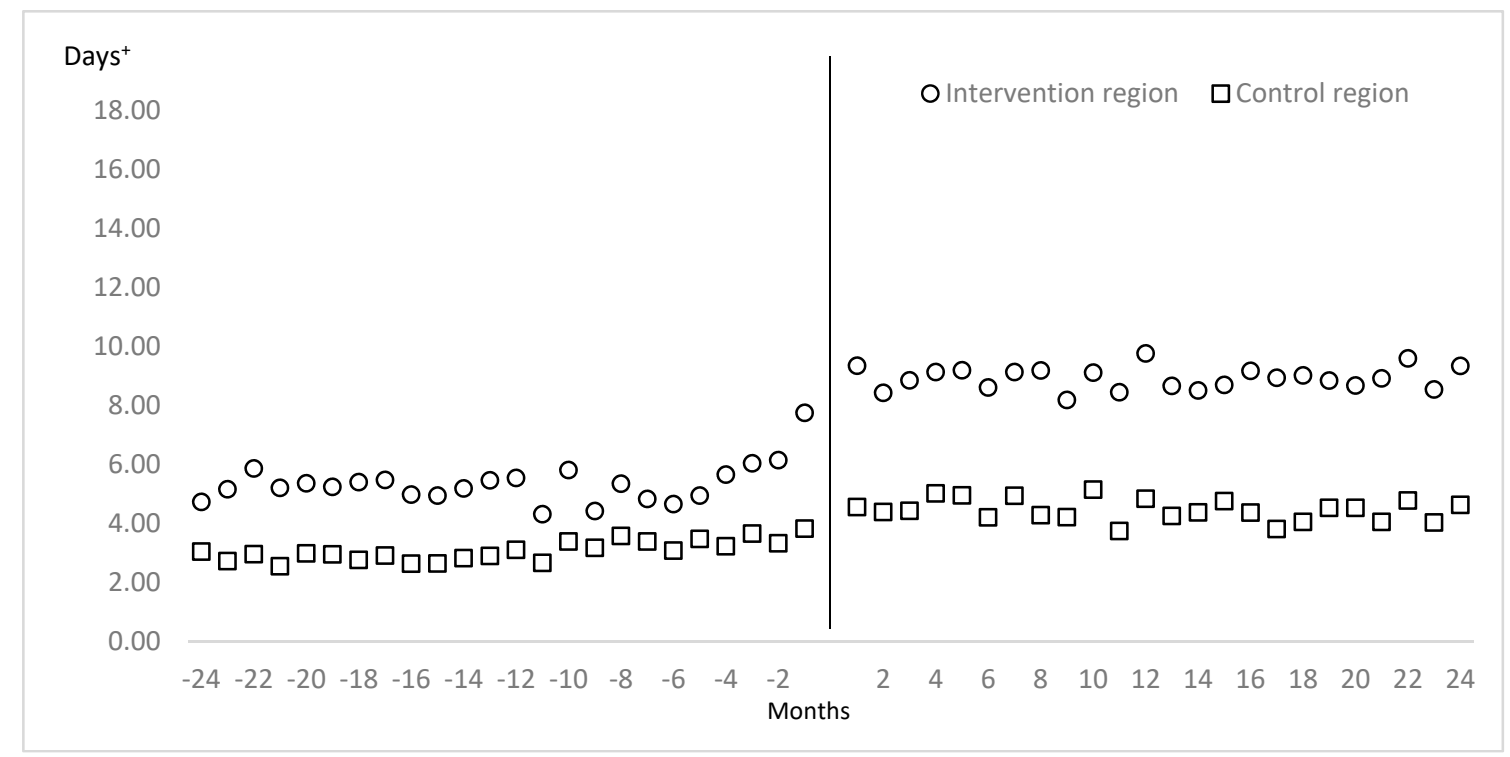

(b)

Figure 2. Comparison of dispensation per prescription (a) and dispensation days per patient with hypertension (b) on pre-intervention and post-intervention between study regions. * Proportion of dispensation per prescription on hypertensive patients during given period. + Dispensed days per patient with hypertension during given period.

\section{Discussion}

\subsection{Comparison with Previous Studies}

Continuous treatment of patients with hypertension is important, including a regular visit (prescription) to healthcare institutions and taking medicine regularly (patients' adherence) due to the purchase of antihypertensive drugs (dispensation) at pharmacies $[15,16]$. Some international studies similar to ours have been conducted in Brazil, Taiwan, the USA, China, Indonesia, England, and Japan [33-39]. Overall, these community-based healthcare programs were an effective means of helping patients' adherence with hypertension. A meta-analysis of community-based interventions, to enhance medication adherence and blood pressure control in hypertension, documented significant but modest post-intervention improvements in blood pressure outcomes among hypertensive 
patients [40]. Even more, supported self-management can improve blood pressure control according to another systematic qualitative and quantitative meta-review [41].

Medication nonadherence is widespread and varied by disease, patient characteristics, and insurance coverage, with nonadherence rates ranging from $25 \%$ to $50 \%$ [42,43]. Approximately $50 \%$ of patients with cardiovascular disease have poor adherence to their prescribed medications [44]. In order to improve medication adherence, clinicians as well as health policy decision makers must understand why patients fail to take prescribed medications, that is, the determinants of medication nonadherence. These determinants can usually be categorized as patient related, provider related, and external factors [30]. Among these factors, this community-based intervention is mainly conducted following the external factors in terms of strengthening the health care system according to the chronic care model [12]. The expected effects of this intervention program include also improved awareness and self-management rate of the target disease (hypertension) through health education and counseling for registered patients and extended healthy lifespan by prevention of complications from cardio-cerebrovascular diseases through continuous management of hypertension $[13,40,41,45]$. Especially our study applied to the Andersen's medical use model as the expected effects of the program, confirming continuous medication adherence [27]. In order to investigate the purpose of our study, the number of patients by insurance benefit days for managing hypertension, proportion of DPP, and DDPP with hypertension were selected as proxy indicators. The trend of patients by insurance benefit days between study regions can be determined by the continuous management level for hypertensive patients within one year. Under KNHI administrative settings, medication adherence can be indirectly obtained through DPP, and the actual effect can be estimated through the DDPP with hypertension. All indicators in Hongcheon County have significantly increased since 2012 , the year in which the community-based intervention was implemented. This confirmed that continuous medication adherence has significantly increased since the program implementation, even after using the difference-in-difference regression analysis [32].

In this rapidly aging society, the incidence rates of hypertension significantly increased with age $[24,46,47]$. During the five-year follow-up, $26.7 \%$ of non-hypertensive individuals developed incident hypertension [46]. Thus, the community-based hypertension control programs have been conducted for more than 10 years in South Korea [13,45,48]. Among them, according to a study that used big data from the NHIS to evaluate the effectiveness of the chronic disease management program in Incheon, the prescription days of outpatients, continuous treatment rate, days of inpatient care, days of outpatient visits, and cost of inpatient and outpatient care in the registered group were higher compared to the non-registered group. Unlike our study; however, the shortcomings of that study were as follows: The research period was relatively short as one year (365 days) before and after intervention; the criteria for selecting the control group were ambiguous; and the intervention and control groups did not match [48].

After the 2012 UN Declaration on the Prevention and Control of NCDs [1], the World Health Organization and the World Heart Federation adopted the global goals "25by25", to reduce early death rates by $25 \%$ due to NCDs by the year 2025 . In addition, they proposed detailed strategies such as reducing the rate of increase in blood pressure by $25 \%$ and maintaining $0 \%$ as the rate of diabetes/obesity [45,49-51]. In order to achieve the Global NCDs Action Plan 2013-2020 in conjunction with the UN's Sustainable Development Goals (SDG) in 2015, investing in NCDs prevention and management (SDG 3.4) is strongly recommended to all countries [52]. Therefore, the Korean government has come to a time for expanding and strengthening from the current pilot stage to the nationwide level through the comprehensive reassessment of the community-based intervention for hypertension control.

\subsection{Methodological Consideration}

Thus, in order to evaluate the effectiveness of the community-based intervention in this study, not only a well-designed research methodology tracking longitudinally but also a sophisticated 
theoretical model should be considered. To minimize the unexpected bias caused by potential confounding variables [25], the eligibility information of KNHI Big Data in our study are refined as follows: First, a control region similar to all characteristics of the intervention region was selected, except the community-based intervention for controlling hypertension. Second, this program is a community-based hypertension intervention that approaches the enabling and need factors according to the Andersen's model [27]. In terms of enabling factors, the center supports elderly patients aged $\geq 65$ years to promote continuous medication adherence. Moreover, the center educates and manages patients so that they become aware of hypertension in terms of need factors. Direct interventions that enable patients to receive continuous medication adherence can be observed as support out-of-pocket payment for medical care and medication fee. Thus, as defined in the community-based intervention, the study subjects determined that elderly patients aged $\geq 65$ years and $<85$ years were only included in the program. Third, the size and characteristics of study subjects between the intervention and control regions were equally matched, 1:1, by establishing a cohort by a non-equivalent control group design in terms of predisposing factors.

Some limitations of this study were identified due to the weakness of the study data. First, we could indirectly check the patients' adherence by this intervention until the dispensation after the prescription using secondary insurance claims data; however, we could not actually determine whether patients' blood pressure was controlled by anti-hypertensive medications. Second, patients with hypertension in 2010 were not included as the study subjects unless they visited the medical institution. Third, there was no confirmation of complications due to hypertension and the medical expenses incurred. Medication nonadherence leads to poor outcomes, which then increase health care service utilization and overall health care costs. Between US $\$ 100$ and US\$ 300 billion of avoidable health care costs have been attributed to nonadherence in the US annually, representing $3 \%$ to $10 \%$ of total US health care costs [30,53]. Lastly, we could not apply the Patient Assessment of Chronic Illness Care instrument [54], including indirectly administrative measurements (MPR, PDC) [28,30] as well as Korean-version eight-item Morisky Medication Adherence Scale (MMAS-K) [55,56] for measuring the extent to which hypertensive patients receive care congruent with the chronic care model.

\section{Conclusions}

In this study, we did a comparative analysis regarding the gap in medication adherence of hypertensive elderly patients based on Andersen's model between Hongcheon County, with the hypertension and diabetes registration and education center, and Hoengseong County, without this center. For the aim of this study, the change in the medication adherence in elderly patients with hypertension before and after implementing the community-based intervention between two regions was verified through descriptive analysis and the difference-in-difference regression analysis using the KNHI Big Data. Summarily, elderly patients with hypertension in Hongcheon County have been receiving continuous management and improving medication adherence compared to those in Hoengseong County, in 2013 and 2014, since this program was implemented. In conclusion, the findings suggest that the community-based intervention for controlling hypertension should expand nationwide in Korea, ahead of a super-aged society. Of course, we need additional information about a delay in the period of developing complications of hypertension within the intervention region. Additionally, we are planning to provide a cost-benefit estimate through rolling out this community-based intervention nationwide in the near future.

Author Contributions: C.-B.K. and B.P. initiated the idea for this study. C.-B.K. is supported by the KCDC and Hongcheon County. K.-J.S. led the formal analysis and data curation. H.-R.S., B.P., and H.-J.K. undertook the investigation. C.-B.K. and K.-J.S. were involved in the methodology of this study. H.-R.S. undertook the project administration. K.-J.S. wrote the initial draft of the article. C.-B.K. reviewed and edited the final draft of the article.

Funding: This research was funded by the Korea Centers for Disease Control and Prevention (KCDC) and Hongcheon County in Kangwon Province grant (\#2017-51-0508). Additionally, this study was supported by a National Research Foundation Grant of Korea, Korean Government (NRF-2016S1A5B892520). The APC was funded by the KCDC and Hongcheon County grant (\#2018-51-0403). 
Acknowledgments: We would like to thank the registered patients with hypertension and all partners (including senior community centers, clinics, and pharmacies) in Hongcheon County for supporting this intervention program. Also, we are grateful to the Division of Chronic Disease Prevention, KCDC and the Health, Welfare and Women's Affairs Bureau, Kangwon Province. The views expressed are those of the authors and not necessarily those of the KCDC.

Conflicts of Interest: The authors declare no potential conflict of interest.

\section{References}

1. United Nations. Political Declaration of the High-Level Meeting of the General Assembly on the Prevention and Control of Non-Communicable Diseases. 3rd Plenary Meeting. 2011. Available online: https:// documents-dds-ny.un.org/doc/UNDOC/GEN/N11/458/94/PDF/N1145894.pdf?OpenElement (accessed on 26 November 2018).

2. Lozano, R.; Naghavi, M.; Foreman, K.; Lim, S.; Shibuya, K.; Aboyans, V.; Abraham, J.; Adair, T.; Aggarwal, R.; Ahn, S.Y.; et al. Global and regional mortality from 235 causes of death for 20 age groups in 1990 and 2010: A systematic analysis for the Global Burden of Disease Study 2010. Lancet 2012, 380, 2095-2128. [CrossRef]

3. Naghavi, M.; Wang, H.; Lozano, R.; Davis, A.; Liang, X.; Zhou, M.; Vollset, S.E.; Ozgoren, A.A.; Abdalla, S.; Abd-Allah, F.; et al. GBD 2013 Mortality and Causes of Death Collaborators. Global, regional, and national age-sex specific all-cause and cause-specific mortality for 240 causes of death, 1990-2013: A systematic analysis for the Global Burden of Disease Study 2013. Lancet 2015, 385, 117-171.

4. Kjeldsen, S.E.; Narkiewicz, K.; Burnier, M.; Oparil, S. The Global Burden of Disease Study 2015 and blood pressure. Blood Press. 2017, 26, 1. [CrossRef] [PubMed]

5. Melaku, Y.A.; Renzaho, A.; Gill, T.K.; Taylor, A.W.; Dal Grande, E.; de Courten, B.; Baye, E.; Gonzalez-Chica, D.; Hyppönen, E.; Shi, Z.; et al. Burden and trend of diet-related non-communicable diseases in Australia and comparison with 34 OECD countries, 1990-2015: Findings from the Global Burden of Disease Study 2015. Eur. J. Nutr. 2018. [CrossRef] [PubMed]

6. Benziger, C.P.; Roth, G.A.; Moran, A.E. The Global Burden of Disease Study and the preventable burden of NCD. Glob. Heart 2016, 11, 393-397. [CrossRef] [PubMed]

7. Statistics Korea. 2017 Cause of Death Statistics. 2018. Available online: http://kostat.go.kr/portal/korea/ kor_nw/2/6/1/index.board?bmode=read\&aSeq=370710 (accessed on 28 November 2018).

8. Lee, Y.H.; Yoon, S.J.; Kim, A.; Seo, H.; Ko, S. Health performance and challenges in Korea: A review of the Global Burden of Disease Study 2013. J. Korean Med. Sci. 2016, 31, S114-S120. [CrossRef] [PubMed]

9. Shin, J.; Lim, J.; Ki, M.; Song, Y.J.; Chun, H.; Kim, D. An assessment of magnitudes and patterns of socioeconomic inequalities across various health problems: A large national cross-sectional survey in Korea. Int. J. Environ. Res. Public Health 2018, 15, 2868. [CrossRef] [PubMed]

10. Whelton, P.K.; He, J.; Appel, L.J.; Cutler, J.A.; Havas, S.; Kotchen, T.A.; Roccella, E.J.; Stout, R.; Vallbona, C.; Winston, M.C.; et al. National High Blood Pressure Education Program Coordinating Committee. Primary prevention of hypertension: Clinical and public health advisory from The National High Blood Pressure Education Program. JAMA 2002, 288, 1882-1888. [CrossRef] [PubMed]

11. Ministry of Health and Welfare; Korea Centers for Disease Control \& Prevention. Introduction for 2017 Community Integrated Health Promotion Program: Prevention and Management for Cardiocerebrovascular Diseases. 2017. Available online: http:/ / www.cdc.go.kr/CDC/together/CdcKrTogether0302.jsp?menuIds= HOME006-MNU2804-MNU3027-MNU2979\&cid=138093 (accessed on 31 October 2018).

12. Glasgow, R.E.; Orleans, C.T.; Wagner, E.H. Does the chronic care model serve also as a template for improving prevention? Milbank Q. 2001, 79, 579-612. [CrossRef] [PubMed]

13. Korea Centers for Disease Control \& Prevention. Standard Administrative Work Guidelines for 2017 Hypertension and Diabetes Registration and Management Program. 2017. Available online: http:/ / www.cdc.go.kr/CDC/together/CdcKrTogether0302.jsp?menuIds=HOME006-MNU2804MNU3027-MNU2979\&cid=138094 (accessed on 31 October 2018).

14. Kim, J.A.; Kim, E.S.; Lee, E.K. Evaluation of the chronic disease management program for appropriateness of medication adherence and persistence in hypertension and type-2 diabetes patients in Korea. Medicine (Baltimore) 2017, 96, e6577. [CrossRef] [PubMed] 
15. Pennant, M.; Davenport, C.; Bayliss, S.; Greenheld, W.; Marshall, T.; Hyde, C. Community programs for the prevention of cardiovascular disease: A systematic review. Am. J. Epidemiol. 2010, 72, 501-516. [CrossRef] [PubMed]

16. Zhang, D.; Wang, G.; Joo, H. A systematic review of economic evidence on community hypertension interventions. Am. J. Prev. Med. 2017, 53, S121-S130. [CrossRef] [PubMed]

17. Eraker, S.A.; Kirscht, J.P.; Becker, M.H. Understanding and improving patient compliance. Ann. Intern. Med. 1984, 100, 258-268. [CrossRef] [PubMed]

18. Lim, D.S. Utilizing the data of health insurance as a source for calculating major epidemiological index of cardiovascular disease. Public Health Wkly. Rep. 2014, 7, 958-962. Available online: http:/ /www.cdc.go.kr/ CDC/info/CdcKrInfo0301.jsp?menuIds=HOME006-MNU3003-MNU2950-MNU2951\&year=2014 (accessed on 31 October 2018).

19. National Health Insurance Service. Sample Cohort 2.0 DB User Manual. 2017. Available online: http:/ / www.nhis.or.kr/bbs7/boards/B0070/6801 (accessed on 31 October 2018).

20. Song, H.J.; Jang, S.M.; Shin, SY. Patterns of medical care utilization behavior and related factors among hypertensive patients: Follow-up study using the 2003-2007 Korean Health Insurance Claims Data. Korean J. Health Educ. Promot. 2012, 29, 1-12.

21. Park, J.H.; Shin, Y.; Lee, S.Y.; Lee, S.I. Antihypertensive drug medication adherence and its affecting factors in South Korea. Int. J. Cardiol. 2008, 128, 392-398. [CrossRef] [PubMed]

22. Shin, S.; Song, H.; Oh, S.K.; Choi, K.E.; Kim, H.; Jang, S. Effect of antihypertensive medication adherence on hospitalization for cardiovascular disease and mortality in hypertensive patients. Hypertens. Res. 2013, 36, 1000-1005. [CrossRef] [PubMed]

23. Kim, H.J.; Moon, K.; Park, T.H.; Park, S.Y.; Yoon, S.J.; Oh, I.H. Factors affecting treatment compliance in new hypertensive patients in Korea. Clin. Exp. Hypertens. 2016, 38, 701-709. [CrossRef] [PubMed]

24. Bromfield, S.G.; Bowling, C.B.; Tanner, R.M.; Peralta, C.A.; Odden, M.C.; Oparil, S.; Muntner, P. Trends in hypertension prevalence, awareness, treatment, and control among US adults 80 years and older, 1988-2010. J. Clin. Hypertens. 2014, 16, 270-276. [CrossRef] [PubMed]

25. Hak, E.; Verheij, T.J.; Grobbee, D.E.; Nichol, K.L.; Hoes, A.W. Confounding by indication in non-experimental evaluation of vaccine effectiveness: The example of prevention of influenza complications. J. Epidemiol. Community Health 2002, 56, 951-955. [CrossRef] [PubMed]

26. Korea Ministry of Government Legislation. National Health Insurance Act (Chapter 2. Article 5, Article 6), Medical Care Assistance Act (Article 2, Article 3). Available online: http:/ / www.law.go.kr/lsSc.do?tabMenuId=tab18\&query=\%EA\%B5\%AD\%EB\%AF\%BC\%EA\%B1\% B4\%EA \%B0\%95\%EB\%B3\%B4\%ED\%97\%98\%EB\%B2\%95\#undefined (accessed on 31 October 2018).

27. Andersen, R.M. Families' Use of Health Services: A Behavioral Model of Predisposing, Enabling, and Need Components; Purdue University: West Lafayette, IN, USA, 1968. Available online: http:/ / docs.lib.purdue. edu/dissertations / AAI6902884/ (accessed on 29 October 2018).

28. LaFleur, J.; Oderda, G.M. Methods to measure patient compliance with medication regimens. J. Pain Palliat. Care Pharmacother. 2004, 18, 81-87. [CrossRef] [PubMed]

29. Jimmy, B.; Jose, J. Patient medication adherence: Measures in daily practice. Oman Med. J. 2011, 26, 155-159. [CrossRef] [PubMed]

30. Iuga, A.O.; McGuire, M.J. Adherence and health care costs. Risk Manag. Healthc. Policy 2014, 7, 35-44. [CrossRef] [PubMed]

31. Nieuwlaat, R.; Wilczynski, N.; Navarro, T.; Hobson, N.; Jeffery, R.; Keepanasseril, A.; Agoritsas, T.; Mistry, N.; Iorio, A.; Jack, S.; et al. Interventions for enhancing medication adherence. Cochrane Database Syst. Rev. 2014, 11, CD000011. [CrossRef] [PubMed]

32. Daw, J.R.; Hatfield, L.A. Matching and regression to the mean in difference-in-differences analysis. Health Serv. Res. 2018, 53, 4138-4156. [CrossRef] [PubMed]

33. Moreira, G.C.; Cipullo, J.P.; Martin, J.F.; Ciorlia, L.A.; Godoy, M.R.; Cesarino, C.B.; Cordeiro, J.A.; Lupino, P.L.; Ciorlia, G.; Burdmann, E.A. Evaluation of the awareness, control and cost-effectiveness of hypertension treatment in a Brazilian city: Populational study. J. Hypertens. 2009, 27, 1900-1907. [CrossRef] [PubMed]

34. Wu, M.P.; Wu, S.F.; Wang, T.C.; Kao, M.J.; Yang, W.L. Effectiveness of a community-based health promotion program targeting people with hypertension and high cholesterol. Nurs. Health Sci. 2012, 14, 173-181. [CrossRef] [PubMed] 
35. Ferdinand, K.C.; Patterson, K.P.; Taylor, C.; Fergus, I.V.; Nasser, S.A.; Ferdinand, D.P. Community-based approaches to prevention and management of hypertension and cardiovascular disease. J. Clin. Hypertens. 2012, 14, 336-343. [CrossRef] [PubMed]

36. Bai, Y.; Zhao, Y.; Wang, G.; Wang, H.; Liu, K.; Zhao, W. Cost-effectiveness of a hypertension control intervention in three community health centers in China. J. Prim. Care Community Health 2013, 4, 195-201. [CrossRef] [PubMed]

37. Rahmawati, R.; Bajorek, B. A community health worker-based program for elderly people with hypertension in Indonesia: A qualitative study, 2013. Prev. Chronic Dis. 2015, 12, E175. [CrossRef] [PubMed]

38. Dregan, A.; Ravindrarajah, R.; Hazra, N.; Hamada, S.; Jackson, S.H.; Gulliford, M.C. Longitudinal trends in hypertension management and mortality among Octogenarians: Prospective Cohort Study. Hypertension 2016, 68, 97-105. [CrossRef] [PubMed]

39. Otani, K.; Haruyama, R.; Gilmour, S. Prevalence and correlates of hypertension among Japanese adults, 1975 to 2010. Int. J. Environ. Res. Public Health 2018, 15, 1645. [CrossRef] [PubMed]

40. Morrissey, E.C.; Durand, H.; Nieuwlaat, R.; Navarro, T.; Haynes, R.B.; Walsh, J.C.; Molloy, G.J. Effectiveness and content analysis of interventions to enhance medication adherence and blood pressure control in hypertension: A systematic review and meta-analysis. Psychol. Health 2017, 32, 1195-1232. [CrossRef] [PubMed]

41. Shahaj, O.; Denneny, D.; Schwappach, A.; Pearce, G.; Epiphaniou, E.; Parke, H.L.; Taylor, S.J.C.; Pinnock, H. Supporting self-management for people with hypertension: A meta-review of quantitative and qualitative systematic reviews. J. Hypertens. 2018. [CrossRef] [PubMed]

42. Haynes, R.B.; Montague, P.; Oliver, T.; McKibbon, K.A.; Brouwers, M.C.; Kanani, R. Interventions for helping patients to follow prescriptions for medications. Cochrane Database Syst. Rev. 2000, 2, CD000011.

43. DiMatteo, M.R. Variations in patients' adherence to medical recommendations: A quantitative review of 50 years of research. Med. Care. 2004, 42, 200-209. [CrossRef] [PubMed]

44. Kronish, I.M.; Ye, S. Adherence to cardiovascular medications: Lessons learned and future directions. Prog. Cardiovasc. Dis. 2013, 55, 590-600. [CrossRef] [PubMed]

45. Park, Y.H. Strategy for noncommunicable disease control and prevention. J. Korean Med. Assoc. 2014, 57, 808-814. [CrossRef]

46. Lee, J.H.; Yang, D.H.; Park, H.S.; Cho, Y.; Jun, J.E.; Park, W.H.; Chun, B.Y.; Shin, J.Y.; Shin, D.H.; Lee, K.S.; et al. The Hypertension-Diabetes Daegu Initiative Study Investigators. Incidence of hypertension in Korea: 5-year follow-up study. J. Korean Med. Sci. 2011, 26, 1286-1292. [CrossRef] [PubMed]

47. Asayama, K.; Satoh, M.; Murakami, Y.; Ohkubo, T.; Nagasawa, S.Y.; Tsuji, I.; Nakayama, T.; Okayama, A.; Miura, K.; Imai, Y.; et al. Evidence for Cardiovascular Prevention from Observational Cohorts in Japan (EPOCH-JAPAN) Research Group. Cardiovascular risk with and without antihypertensive drug treatment in the Japanese general population: Participant-level meta-analysis. Hypertension 2014, 63, 1189-1197. [CrossRef] [PubMed]

48. Cheong, W.; Yim, J.; Oh, D.K.; Im, J.S.; Ko, K.P.; Park, I.B. The effect of a clinic-based incentive program on medication adherence among patients with hypertension or diabetes mellitus in Incheon. Health Policy Manag. 2013, 23, 427-433. [CrossRef]

49. World Health Organization. Sixty-Fifth World Health Assembly Resolutions, Decisions, Annexes. WHA65/2012/REC/1. Geneva, Switzerland, 21-26 May 2012. Available online: http://apps.who.int/ $\mathrm{gb} /$ or/e/e_wha65r1.html (accessed on 29 October 2018).

50. Smith, S.C., Jr.; Chen, D.; Collins, A.; Harold, J.G.; Jessup, M.; Josephson, S.; Logstrup, S.; Sacco, R.L.; Vardas, P.E.; Wood, D.A.; et al. Moving from political declaration to action on reducing the global burden of cardiovascular diseases: A statement from the Global Cardiovascular Disease Taskforce. J. Am. Coll. Cardiol. 2013, 62, 2151-2153. [CrossRef] [PubMed]

51. James, P.A.; Oparil, S.; Carter, B.L.; Cushman, W.C.; Dennison-Himmelfarb, C.; Handler, J.; Lackland, D.T.; LeFevre, M.L.; MacKenzie, T.D.; Ogedegbe, O.; et al. 2014 evidence-based guideline for the management of high blood pressure in adults: Report from the panel members appointed to the Eighth Joint National Committee (JNC 8). JAMA 2014, 311, 507-520. [CrossRef] [PubMed]

52. Nugent, R.; Bertram, M.Y.; Jan, S.; Niessen, L.W.; Sassi, F.; Jamison, D.T.; Pier, E.G.; Beaglehole, R. Investing in non-communicable disease prevention and management to advance the Sustainable Development Goals. Lancet 2018, 391, 2029-2035. [CrossRef] 
53. Benjamin, R.M. Medication adherence: Helping patients take their medicines as directed. Public Health Rep. 2012, 127, 2-3. [CrossRef] [PubMed]

54. Gugiu, P.C.; Coryn, C.; Clark, R.; Kuehn, A. Development and evaluation of the short version of the Patient Assessment of Chronic Illness Care instrument. Chronic Illn. 2009, 5, 268-276. [CrossRef] [PubMed]

55. Morisky, D.E.; Ang, A.; Krousel-Wood, M.; Ward, H.J. Predictive validity of a medication adherence measure in an outpatient setting. J. Clin. Hypertens. 2008, 10, 348-354. [CrossRef]

56. Sohn, H.S.; Jang, S.; Lee, J.Y.; Han, E. Patient response to insurer-led intervention for medication adherence-A pilot study based on claims data in Korea. Int. J. Clin. Pharmacol. Ther. 2016, 54, $28-35$. [CrossRef] [PubMed]

(C) 2019 by the authors. Licensee MDPI, Basel, Switzerland. This article is an open access article distributed under the terms and conditions of the Creative Commons Attribution (CC BY) license (http:/ / creativecommons.org/licenses/by/4.0/). 